\title{
A Clinical Study on Hyponatremia in Elderly, Hospitalized Patients
}

\author{
P. Shashikath Reddy ${ }^{1}$, Harish Katragadda ${ }^{2}$ \\ ${ }^{1}$ Associate Prof. Of medicine RVM Medical College, Medak, Telangana, ${ }^{2}$ Assistant Prof. Of Medicine, NRI medical College, Guntur, AP.
}

\section{Abstract}

Background: Electrolytes abnormalities are very common abnormalities in elderly individuals, among these hyponatramia is very dangerous and with high mortality hyponatramia is labelled as when serum sodium is less than $135 \mathrm{~m} . \mathrm{eq} / \mathrm{l}$. It is associated with profound disturbance of cerebral function. Clinical features of hyponatremia include confusion, lethargy, vomiting convulsions and coma. To most cases of hypomatremiareflects water imbalance and abnormal water handling not sodium. Rapid rate of development of electrolyte abnormality causes more severe cerebral symptoms than the levels of $\mathrm{Na}$ Aggressive treatment and inappropriate therapy is more harmful than hyponatremia. Common causes of hyponatremia are dehydration, chronic renal failure, AIDS, Hypothyroidism and infections. Aim: To study the pattern, clinical features and outcome of patients with hyponatremia. Subjects and Methods: This study in conducted for 1year in 2 rural medical colleges in Telangana and Andhra Pradesh we have conducted this study on 80 elderly patients. Hospitalized patients. The age group is between 6.5 and 80 years males were 54 and females were 36. Results: We have examined 80 patients, males were 54 and females were 36 . The age group is between 65 and 80 years. Hyponatremia was observed in 28 patients out of these 28 patients males were 18 and females were 10. The common age group is between 70 and 75 years. Conclusion: Hyponatremia is very common in elderly patients. And it is mostly seen in pts withCVA CAD, diabetes and sepsis. So when the elderly patients admitted with these coma bid conditions look for the early symptoms of hyponatremia and serum electrolyte should be tested. Early detection and early managements can prevent the mortality and morbidity is these patients.

Keywords: Electrolyte abnormalities, Hyponatremia elderly patients, altered sensorium, serum sodium, morbidity.

Corresponding Author: Dr. Harish Katragadda, Assistant Prof. Of Medicine, NRI medical College, Guntur, AP.

Received: September 2019

Accepted: October 2019

\section{Introduction}

The total body fluid is distribution mainly between 2 compartments. The extracellular fluid and intracellular fluid the extracellular fluid in divided into interstitial fluid and blood plasma. ${ }^{[1]}$ Sodium, potassium and chlorides are in extracellular fluid compartment the total body water ingested in the form of liquid or water in the food is $2100 \mathrm{ml} /$ day. The water synthesised in the body as a result of oxidation of carbohydratesis about $200 \mathrm{ml} /$ day, so total body intake in about $2300 \mathrm{ml} /$ day. ${ }^{[2]}$ Daily loss of body water through skin and resp. tract is $700 / \mathrm{ml} /$ day, through sweat is $100 \mathrm{ml} /$ day and through faces is $100 \mathrm{ml}$ and through kidney is $500 \mathrm{ml} /$ day. When the sodium concentration is reduced to less than $135 \mathrm{mEq} / 1$ is called hyponatramia when $142 \mathrm{meq} 1 / 1$ exceeds is called hyponatremia. ${ }^{[3]}$ A Common misconception is that the sodium concentration is a reflection of total body water or sodium. In fact total body water and sodium can be low normal or high in hyponatremia since the kidney independently regulates sodium and water homeostasis. ${ }^{[4]}$ $\mathrm{ADH}$ got primary role in patho physiology of hyponatremia. Serum osmollity identifies isotonic and hypertonic hyponatramiaisotonichyponatramea is seen with severehyponatramia and hyponatramic and hyprotonic hyponatremia occurs with mannitol administration for increased intracranial pressure. Glucose and mannitol osmotically pull intracellular water into the extracellular space. The $\mathrm{Na}$ Concentration Fall 2Meq/l for every $100 \mathrm{mg} / \mathrm{dl}$. Rise in glucose concentration is between $200 \mathrm{mg} / \mathrm{dl}$ and $400 \mathrm{mg} / \mathrm{dl} .{ }^{[5,6]}$

Hypotonic hypernatremia is common than other types or it is sub divided into hypovolemia hypotonic hyponatremia euvolrmic hypotonic hyponatremia and hypervolemic hypotonic hyponatremia. ${ }^{[7]}$ The causes of hyponatrimic hyponatremia are dehydrates, diarrheal and vomiting, diuretics and cerebral $\mathrm{Na}$ wasting syndrome.

The cause of euvolemi hyponatremia are SIADH, Hypothysoidism, psychogenic polyolypsia and heart failure, liver disease can cause hypervolemic hyponatremia. ${ }^{\left[{ }^{[3}\right.}$

Hyponatremia is seen up to $50 \%$ of hospitalized HIV patients and $20 \%$ ambulatory HIV patients. Clinical features includes lethargy, weakness, attered sensorium, convulsions, coma: chronic disease can be severe $\mathrm{Sr}$. $\mathrm{Na}<110 \mathrm{meq} / \mathrm{l}$, yet remarkably asymptamatic because the brain has adopted by decreasing its tonicity over weaks to months. Mild hyponatramia $\mathrm{Sr} \mathrm{Na}$ is beteen $130 \mathrm{Meq} . / \mathrm{l}$ to $135 \mathrm{Meq} / \mathrm{l}$. Is usually asymptamatic. Pre menpousal women are much more likely than menopausal women to die or suffer perment brain damage from hyponatremic encephalopathy, suggesting a hormonal role in pathophysiology. ${ }^{[9]}$ 


\section{Subjects and Methods}

This is conducted in 80 patients males were 54 and females were36. Age group is between 65 and 80 year. The maximum no. Of patients were between $65 \mathrm{yr}-69 \mathrm{yr}$. The no. of patients was $38(47.56 \%)$. The minimum no. of patients were above 80 years $6(7.5 \%) .12$ patients expired. Maximum morlality is observed in above 75years causes include other comorbid conditions like cerebrovascula accidents diabetes, reval failure and sepsis.

\section{Results}

Out of 80 patients males were 54 and females were 36 . Severs hyponatremia is observed in 12 patients.in those patients serum $\mathrm{Na}$ is less than $110 \mathrm{~m}$ eq/1 mild hyponatremia was observed in 25 patients. The serum $\mathrm{Na}$ is these patients were between $130 \mathrm{~m} \mathrm{eq} / 1$ and $135 \mathrm{~m}$ eq/l.

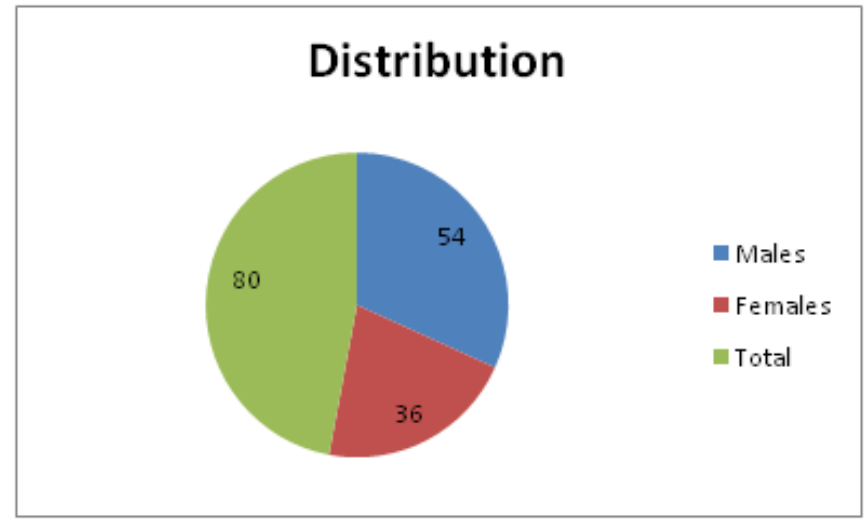

\section{Chart 1:}

\section{Age wise Distribution}

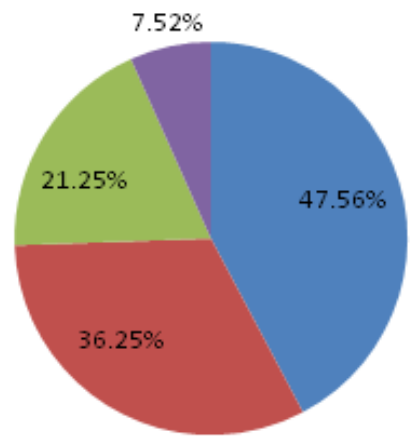

$65-69 y r s$

$70-79 y r s$

$75-80 \mathrm{yrs}$

above $80 y r s$

\section{Chart 2:}

Table 1: Age wise distribution
\begin{tabular}{|l|l|l|l|}
\hline S.no & Age yr & No of pt & Percentage \\
\hline 1 & $65-89 \mathrm{yr}$ & 38 & $47.56 \%$ \\
\hline 2 & $70-74 \mathrm{yr}$ & 29 & $36.25 \%$ \\
\hline 3 & $75-80 \mathrm{yr}$ & 17 & $21.26 \%$ \\
\hline 4 & $>80 \mathrm{yr}$ & 6 & $9.52 \%$ \\
\hline
\end{tabular}

Table 2: Different levels of so. No extents

\begin{tabular}{|l|l|l|l|}
\hline S.no & Sr. no $\mathbf{~ m . g m} / \mathbf{l}$ & No. Of. Pts & Percentage \\
\hline 1 & $135-130$ & 25 & $31.25 \%$ \\
\hline 2 & $125-130$ & 29 & $36.28 \%$ \\
\hline 3 & $120-125$ & 14 & $17.56 \%$ \\
\hline 4 & $115-120$ & 12 & $15.05 \%$ \\
\hline
\end{tabular}

\section{Discussion}

The investigations advised are blood sugar, TC, DC, Urea, Serum creatne 12 patients were expired during hospital stay. The common causes observed were higher age group and co morbid conditions like carabro vascular accidents, diabetes, revel failure and sepsis.

Discussion: In our study the patients with serum sodium between 130 and $135 \mathrm{meq} / \mathrm{L}$ rarely have symptoms. The CNS Symptoms reasons systems like, altered sensorium, convulsions and coma were observed in patients with serum sodium around $125 \mathrm{~m} . \mathrm{eq} / \mathrm{l}$. The study conducted by Al Abri et al shows similar results ${ }^{[9]} \mathrm{CT}$ scan was done for all the patients, there was no structural abnormality in CT Scan Brain, all these symptoms were attributed to low serum sodium levels only.

The patients with CNS symptoms were treated with intravenous 3\% saline infusion to raise their sodium levels by $0.5 \mathrm{~m} . \mathrm{m} / \mathrm{hr}$ to maximum of $12 \mathrm{~mm} / \mathrm{l} / \mathrm{hr}$. Recent data show that rate of correction has little affect on central positive my lionises. In males mortality is higher when compared with females. May be related to age related to age related brain atrophy. The studies conducted by John kugler et al shows similar results. ${ }^{[10]}$

Co morbid conditions like hypertension, diabetes coronary artery disease, renel failure, and drugs like ARBS increases the rate of hospitalization in patients with hyponatremia In general plasma sodium shall not be corrected to more than 125 to $130 \mathrm{meg} / \mathrm{l}$ assuming that total body water comprise $50 \%$ of total body wt. $1 \mathrm{mg} / \mathrm{kg}$ of $3 \%$ sodium chloride will raise the plasma sodium by $1 \mathrm{mg} / \mathrm{l}$.

\section{Conclusion}

Hyponatremia is very common in elderly patients. And it is mostly seen in pts withCVA CAD, diabetes and sepsis. So when the elderly patients admitted with these coma bid conditions look for the early symptoms of hyponatremia and serum electrolyte should be tested. Early detection and early managements can prevent the mortality and morbidity is these patients.

\section{References}

1. Gcyton Ac Grames HJ. Taylor E: Interstitial fluid pressure. Physiol. Rev. 51:527.1971.

2. Ashceoft fm. From molecule to malady. Nature 440:436.39.2006

3. Raynolds CM, padfield PL, Disorders of sodium balance $\mathrm{Br}$. Med:J.332:702.2006.

4. Sam $\mathrm{R}$ et al. Understanding hypernatremia. AMJ. Nephrol. 2012:36(1).97-104. (Pm20: 2273933).

5. LehrichRw et al Role of vaptans in the management of hyponatremia AMJ. Kidney dis. 2013. August 62(2):364.76.(PMID.23725974).

6. LehrichRw et al Role of vaptans in the management of hyponatremia. AMJ. Kidney dis. 2013. August 62(2):364.76.(PMID.23725974).

7. Current medical diagnosis and treatment chapter 21, pp: 869-7:2016. 
8. Dubois Gd. Brief Al. Symplamatic hyponatremia the case for rapid correction. RG New york. Churchil livingstone 1984: 339-407.

9. Verbalis JG et al diagnosis, evaluation and treatment of hyponatremia. Expert pannel recomondaions. Am JMed. 2013 out: 126: S1-
42)(PMID:24074529).

10. John kugler et al diagnostic strategies in fluid and electrolyte and acid base balance AMJ. 1982; 72(3) 495-52.

Copyright: () the author(s), 2019. It is an open-access article distributed under the terms of the Creative Commons Attribution License (CC BY 4.0), which permits authors to retain ownership of the copyright for their content, and allow anyone to download, reuse, reprint, modify, distribute and/or copy the content as long as the original authors and source are cited.

How to cite this article: Reddy PS, Katragadda H. A Clinical Study on Hyponatremia in Elderly, Hospitalized Patients. Acad. J Med. 2019;2(2):141-43.

DOI: dx.doi.org/10.21276/ajm.2019.2.2.36

Source of Support: Nil, Conflict of Interest: None declared. 